\title{
First records of the Palaestes abruptus Sharp, 1899 and P. nicaraguae Sharp, 1899 (Coleoptera: Cucujidae) from South America, with a checklist of flat bark beetles from the continent
}

\author{
Radomir Jaskuła ${ }^{\ddagger}$, Marek Michalski§, John W. M. Marrisl \\ $\ddagger$ Department of Invertebrate Zoology and Hydrobiology, Faculty of Biology and Environmental Protection, \\ University of Lodz, Łódź, Poland \\ $\S$ Department of Experimental Zoology and Evolutionary Biology, Faculty of Biology and Environmental Protection, \\ University of Lodz, Łódź, Poland \\ | Entomology Research Collection, Bio-Protection Research Centre, Lincoln University, Christchurch, New Zealand
}

Corresponding author: Radomir Jaskuła (radomir.jaskula@biol.uni.lodz.pl)

Academic editor: Yasen Mutafchiev

Received: 29 Dec 2020 | Accepted: 04 Feb 2021 | Published: 17 Feb 2021

Citation: Jaskuła R, Michalski M, Marris JWM (2021) First records of the Palaestes abruptus Sharp, 1899 and

P. nicaraguae Sharp, 1899 (Coleoptera: Cucujidae) from South America, with a checklist of flat bark beetles from the continent. Biodiversity Data Journal 9: e62576. https://doi.org/10.3897/BDJ.9.e62576

\begin{abstract}
\section{Background}

The flat bark beetles (Coleoptera: Cucujidae) is a small insect family with only about 70 species. Most of the species are distributed in Holarctic, Oriental and/or Australasian realms, while in South America, only six species have been recorded, including a single one known from Peru.
\end{abstract}

\section{New information}

Two cucujid beetle species, Palaestes abruptus Sharp, 1899 and P. nicaraguae Sharp, 1899, are recorded from South America for the first time. The species are recorded from the Pasco ( $P$. abruptus) and Cusco and Junín ( $P$. nicaraguae) Regions of Peru, based, in 
part, on data collected through the iNaturalist citizen science database. Habitats of both species are presented in photographs for the first time. A country-level checklist to Cucujidae species currently known from South America is provided.

\section{Keywords}

Palaestes, Thesaurus, Cucujidae, Coleoptera, Brazil, Ecuador, Peru, Venezuela, checklist, iNaturalist, citizen science

\section{Introduction}

The flat bark beetles (Coleoptera: Cucujidae) form a small insect family which includes five genera and almost 70 species and is distributed worldwide, except for Africa, Antarctica, most of the oceanic islands and the greater part of the Arctic (Thomas 2003, Lee and Satô 2007, Lee and Pütz 2008, Horák and Chobot 2009, Lee and Thomas 2011, Bonacci et al. 2012, Marris and Ślipiński 2014, Bussler 2017, Marris 2017, Háva et al. 2019, Zhao and Zhang 2019, Hsiao 2020, Jaskuła et al. 2020, Jin et al. 2020). The South American cucujid fauna is represented by two genera belonging to the subfamily Platisinae: Palaestes Perty, 1830 and Thesaurus Jin, Zwick, Ślipiński, Marris, Thomas \& Pang 2020. Until now, only one species, Thesaurus zaitsevi Jin, Zwick, Ślipiński, Marris, Thomas \& Pang 2020 has been confirmed from Peru (Jin et al. 2020).

This paper presents the first confirmed occurrence of the genus Palaestes Perty, 1830 from Peru, based on records of Palaestes abruptus Sharp, 1899 and $P$. nicaraguae Sharp, 1899. These are also the first records of these species from South America. A checklist of the flat bark beetle species, known from South America, is given.

\section{Materials and methods}

South America ranks as the fourth largest continent, with an area of almost 18 million square kilometres. Brazil is the largest country, encompassing around half of the continent's land area. The greater part of northern and central regions of South America (much of Brazil, Colombia, Ecuador, Guyana, French Guiana, Suriname, most of Peru, north-eastern Paraguay and Venezuela) fall within the tropical and subtropical climatic zones, with a mainly temperate climate in the southern regions. The western part of the continent is characteristically arid (areas in Chile, Peru, Argentina and Paraguay), while a cold, polar climate is present only in southern regions of Argentina and Chile (Beck et al. 2018). As a consequence of its climatic conditions and diverse topography, South America is one of the most biodiverse continents on Earth with thousands of endemic species (Myers et al. 2000).

This project was prompted from viewing a single male Palaestes abruptus from Peru (Pasco Region, Oxapampa Province, Pozuzo District, 5 km E Santa Rosa, 10.0006S, 75.479W, $1150 \mathrm{~m}$ a.s.I., 25.11.2016) in a photo published on the iNaturalist website 
(www.inaturalist.org). The iNaturalist site allows observers from around the world to post images of organisms on the website, while others provide identifications. Although the observer of the Palaestes abruptus photograph (www.inaturalist.org/observations/ 36220768) was unable to send the material for study, he provided information that allowed RJ to contact Mr. Pavel Udovichenko, an insect dealer in Russia, who had additional material of this species. Subsequently, two male specimens were received from this seller. Moreover, Mr. Andrey Azarov sent us a pair of Palaestes nicaraguae adults for study. These specimens are currently deposited in the first author's collection (RJC). Three further specimens from Peru were examined by JM from loan material from the Florida State Collection of Arthropods, Gainesville, Florida, USA (FSCA), provided by the late Michael Thomas.

The specimens examined in this study were identified, based on the original species descriptions (Sharp 1899) and by comparison with photographs of type material.

\section{Taxon treatments}

\section{Palaestes abruptus Sharp, 1899}

\section{Material}

a. higherClassification: Animalia; Arthropoda; Insecta; Coleoptera; Cucujidae' Palaestes; kingdom: Animalia; phylum: Arthropoda; class: Insecta; order: Coleoptera; family: Cucujidae; genus: Palaestes; specificEpithet: abruptus; higherGeography: South America; Peru; Pasco Region; Oxapampa Province; Pozuzo District; Pozuzo; continent: South America; country: Peru; countryCode: PE; stateProvince: Pasco Region; county: Oxapampa Province; municipality: Pozuzo District; locality: Pozuzo; verbatimElevation: 750-1430 m; eventDate: 2019-11; year: 2019; month: 11; habitat: mountain rain forest; eventRemarks: col. Alexander Sokolov; sex: 2 males; lifeStage: adult; identifiedBy: Radomir Jaskuła; dateldentified: 2020-12; identificationReferences: Sharp 1899; identificationRemarks: Pictures of type material were used to confirm identification; collectionID: RJC (Radomir Jaskuła Collection, Łódź, Poland); ownerInstitutionCode: RJC/CUC-0008; RJC/CUC-0009; basisOfRecord: PreservedSpecimen

\section{Description}

Small beetles with strongly flattened bodies; body length (measured from the top of clypeus to the end of elytra) of two studied Peruvian males: $14.7 \mathrm{~mm}$ (Fig. 1a) and 13.6 mm (Fig. 1b). Head black with mandibles black; pronotum yellow-orange; basal part of elytra yellow-orange, while the second half is black; scutellum black; antennae black, except for the last two antennomeres which are brown-orange; legs yellow-orange, except apical parts of femur, tibia and tarsus which are black; tarsal claws brownorange. Sexual dimorphism very visible with males having very large mandibles. 


\section{Distribution}

Previously, this species was only known from Panama and Costa Rica (Sharp 1899, Jin et al. 2020). The locality is mountainous rain forest at altitudes ranging from 750 to $1430 \mathrm{~m}$ (Fig. 2). This is the first record from Peru and South America.

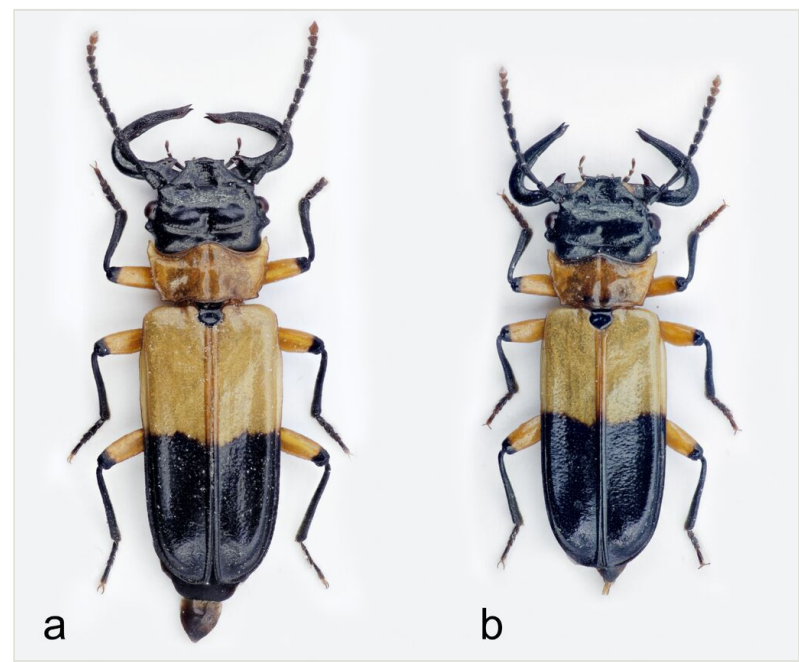

Figure 1. doi

Palaestes abruptus - two males (a-b) from Pasco Region, Peru (photo Marek Michalski).

\section{Ecology}

Cucujidae larvae and adults are known to live under the bark of dead trees (Thomas and Leschen 2010); however, very little is known about biology and ecology of the Palaestes species. Sharp (1899) reported that "Mr Champion informs me that these insects are chiefly found between the thin crevices of sappy timber, and that they are often seen on the wing in forest clearings". This indicates that the habit of Palaestes is similar to that of other cucujids. The only published account of the biology specifically for $P$. abruptus was by Jin et al. (2020), who recorded the only known larva of the species from a rotten log in Costa Rica, found in association with an adult female. Palaestes larvae and adults are probably predatory on small invertebrates living under the bark of dead trees, as has been noted for Platisus zelandicus Marris \& Klimaszewski, 2001 (Watt et al. 2001) and Cucujus spp. (e.g. Palm 1941, Mamaev et al. 1977, Smith and Sears 1982, Horák and Nakládal 2009, Mazzei et al. 2011, Bonacci et al. 2012, Bonacci et al. 2020, Zdeněk et al. 2012). However, it cannot be excluded that they feed also as scavengers or as opportunistic omnivores, feeding on various types of organic debris, such as wood and phloem debris, as recorded for some Cucujus species (Nikitskiy et al. 2000, Horák and Nakládal 2009, Horák 2011). Detailed studies of the phenology, food and habitat preferences and behaviour of Palaestes species are needed. 


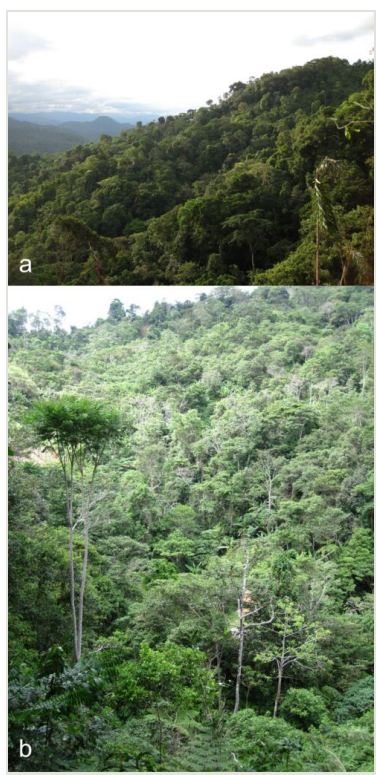

Figure 2. doi

Habitat of Palaestes abruptus in Pasco Region, Peru: general view of the mountains (a), rain forest (b) (photo Alexander Sokolov).

\section{Palaestes nicaraguae Sharp, 1899}

\section{Materials}

a. higherClassification: Animalia; Arthropoda; Insecta; Coleoptera; Cucujidae' Palaestes; kingdom: Animalia; phylum: Arthropoda; class: Insecta; order: Coleoptera; family: Cucujidae; genus: Palaestes; specificEpithet: nicaraguae; higherGeography: South America; Peru; Junín Region; Satipo Province; Satipo District; 15 km N-NW from Satipo; Rio Venado vill.; continent: South America; country: Peru; countryCode: PE; stateProvince: Junín Region; county: Satipo Province; municipality: Satipo District; locality: Rio Venado vill., 15 km N-NW from Satipo; verbatimElevation: 1300 m; verbatimCoordinates: $11^{\circ} 11.32 \mathrm{~S} 74^{\circ} 46.03 \mathrm{~W}$; eventDate: 2019-11-01; year: 2019; month: 11; day: 1; habitat: mountain rain forest; eventRemarks: col. Alexander Petrov; sex: 1 male, 1 female; lifeStage: adult; identifiedBy: Radomir Jaskuła; dateldentified: 2020-12; identificationReferences: Sharp 1899; identificationRemarks: Pictures of type material were used to confirm identification; collectionID: RJC (Radomir Jaskuła Collection, Łódź, Poland); ownerlnstitutionCode: RJC/CUC-0010; RJC/CUC-0011; basisOfRecord: PreservedSpecimen

b. $\quad$ kingdom: Animalia; phylum: Arthropoda; class: Insecta; order: Coleoptera; family: Cucujidae; genus: Palaestes; specificEpithet: nicaraguae; higherGeography: South America; Peru; Cusco Region; Sancurtambo; Santa Isabel; Cosnipata [Kosñipata] Valley Rain Forest Alt. $5525 \mathrm{ft}$; continent: South America; country: Peru; countryCode: PE; stateProvince: Cusco Region; locality: Cosnipata [Kosñipata] Valley Rain Forest Alt. 5525 ft.; eventDate: 1951-12-14; year: 1951; month: 12; day: 14; eventRemarks: col. F Woytkowski; sex: male; lifeStage: adult; associatedOccurrences: NCBI BioSample ID: 
SAMN10963593; associatedSequences: GenBank: No. MK614522; identifiedBy: Mengjie Jin; dateldentified: 2019; identificationReferences: Sharp 1899; identificationRemarks: Pictures of type material were used to confirm identification; collectionID: FSCA (Florida State Collection of Arthropods, Gainesville, Florida, USA); basisOfRecord: PreservedSpecimen

c. higherClassification: Animalia; Arthropoda; Insecta; Coleoptera; Cucujidae' Palaestes; kingdom: Animalia; phylum: Arthropoda; class: Insecta; order: Coleoptera; family: Cucujidae; genus: Palaestes; specificEpithet: nicaraguae; higherGeography: South America; Peru; Cusco Region; Sancurtambo; Santa Isabel; Cosnipata [Kosñipata] Valley Rain Forest Alt. 5525 ft.; continent: South America; country: Peru; countryCode: PE; stateProvince: Cusco Region; locality: Cosnipata [Kosñipata] Valley Rain Forest Alt. 5525 ft.; eventDate: 1951-12-14; year: 1951; month: 12; day: 14; eventRemarks: col. H. L. Dozier; sex: male; lifeStage: adult; identifiedBy: Mengjie Jin; dateldentified: 2019; identificationReferences: Sharp 1899; identificationRemarks: Pictures of type material were used to confirm identification; collectionID: FSCA (Florida State Collection of Arthropods, Gainesville, Florida, USA); basisOfRecord: PreservedSpecime

d. higherClassification: Animalia; Arthropoda; Insecta; Coleoptera; Cucujidae' Palaestes; kingdom: Animalia; phylum: Arthropoda; class: Insecta; order: Coleoptera; family: Cucujidae; genus: Palaestes; specificEpithet: nicaraguae; higherGeography: South America; Peru; Cusco Region; Quiroz; Rio Paucartambo; continent: South America; country: Peru; countryCode: PE; stateProvince: Cusco Region; locality: Quiroz, Rio Paucartambo; eventDate: 1933-11-23; year: 1933; month: 11; day: 23; sex: female [genitalia dissected]; lifeStage: adult; identifiedBy: John W.M. Marris; dateldentified: 2020-12; identificationReferences: Sharp 1899; identificationRemarks: Pictures of type material were used to confirm identification; collectionID: FSCA (Florida State Collection of Arthropods, Gainesville, Florida, USA); basisOfRecord: PreservedSpecimen

\section{Description}

Small beetles with strongly flattened bodies; body length (measured from the top of clypeus to the end of elytra) from $10.2 \mathrm{~mm}$ (female, Fig. 3b) to $10.4 \mathrm{~mm}$ (male, Fig. 3a). Sexual dimorphism clearly visible with males having very large mandibles.

The Peruvian specimens match closely with the holotype of $P$. nicaraguae, based on examination of photographs of the holotype (held in the Natural History Museum, London). The specimens from Peru share the following distinctive characteristics: head, mandibles and prothorax orange-brown, scutellum orange-brown, legs with femorae orange-brown and tibiae and tarsi black, tarsal claws brown-orange and elytra with black colouration extending apically from about the basal $1 / 3$ to $2 / 5$. The only notable difference is that, in the specimens from Peru, the antennomeres dark brown to black, except for the last two apical segmenta, which are red-brown. In contrast, the holotype has three apical segments that are red-brown.

\section{Distribution}

Previously, this species was known only from Nicaragua (Sharp 1899, Jin et al. 2020). The locality is placed in mountainous rain forest at altitudes from 1100 to $1350 \mathrm{~m}$ a.s.l. (Fig. 4). These are the first records from Peru and South America. 


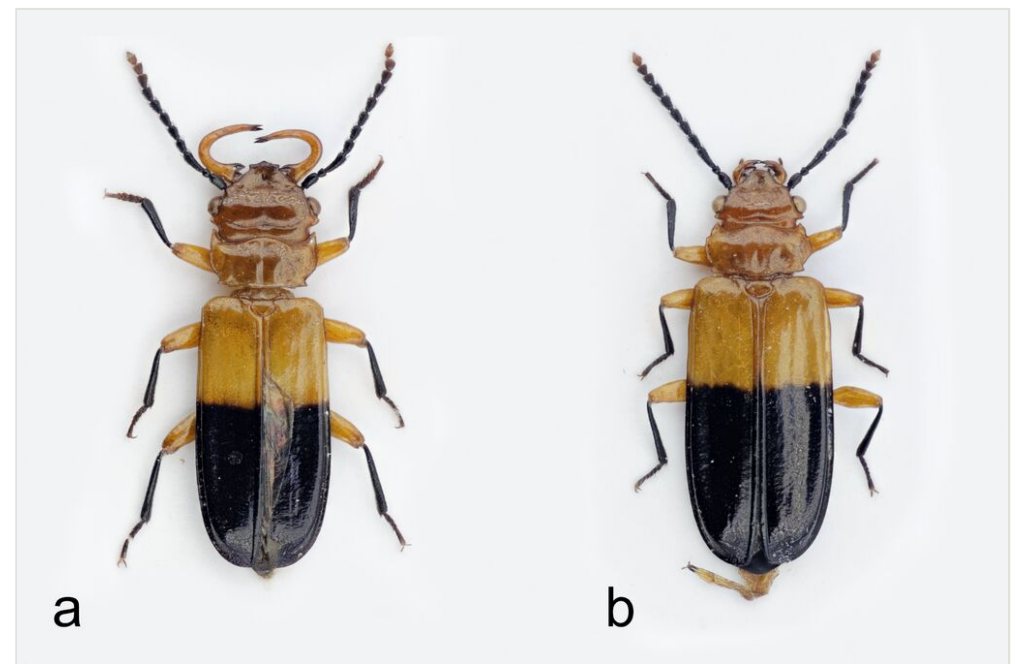

Figure 3. doi

Palaestes nicaraguae - male (a) and female (b) from Junín Region, Peru (photo Marek Michalski).

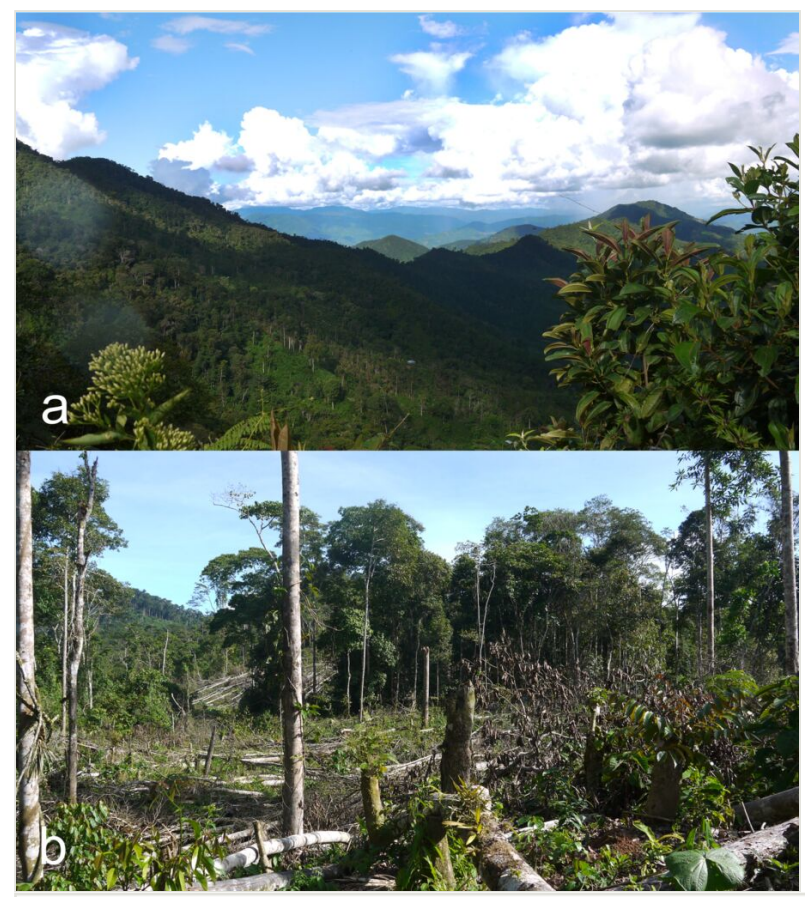

Figure 4. doi

Habitat of Palaestes nicaraguae in Junín Region, Peru: general view (a), felled trees (b) (photo Alexander Petrov). 


\section{Ecology}

As noted for $P$. abruptus, the larvae and adults of $P$. nicarague are presumed to live under the bark of dead trees, where they most probably prey on small insects and larvae. There are no published accounts of the ecology and biology specifically for $P$. nicaraguae.

\section{Discussion}

The flat bark beetle fauna (Coleoptera: Cucujidae) of South America has never been intensively studied and only a few papers have focused on the insect family in South America. For Palaestes Perty, 1830, original species descriptions were provided by von Heyden (1827) for $P$. freyreissi (described as Cucujus), by Perty (1830) for $P$. bicolor, by Guérin-Méneville (1844) for $P$. mandibularis and P. freyersi (both noted as Cucujus) and by Gray (1832) for $P$. dejeani (described as Cucujus) from Brazil (the last four names are recognised as junior synonyms of $P$. freyreissi (von Heyden, [1827]) (Hetschko 1930) and by Waterhouse (1880) for $P$. nigriceps and $P$. tenuicornis from Ecuador. More recently, Jin et al. (2020) described one new genus, Thesaurus, with three species; one from Peru (Thesaurus zaitsevi), one from Venezuela ( $T$. albertalleni) and one from Ecuador (T. macclarini). Two species of Palaestes: P. nigriceps Waterhouse, 1880 and $P$. tenuicornis Waterhouse, 1880, were erroneously recorded from Peru by Blackwelder (1945) in his checklist of South American beetles. The loci typici (and the only currently known locations) for these species are in Ecuador, from Chiguinda and Sarayacu [Sarayaku], respectively, as stated by Waterhouse (1880) in the first paragraph of his article. Adding to the confusion, Thomas and Chaboo (2015) noted the occurrence of one genus (presumably Palaestes) and three species of Cucujidae in Peru, but later stated that only $P$. tenuicornis was present. Thomas and Chaboo (2015) noted the error in listing the distribution of $P$. nigriceps from Peru by Blackwelder (1945) but, surprisingly, not for his record for $P$. tenuicornis. They also recorded $P$. freyreissi (von Heyden, [1827]) and $P$. nigriceps from South America, but absent from Peru (Thomas and Chaboo 2015). In addition, three Brazilian localities for $P$. freyreissi are published in the GBIF database (www.gbif.org).

This paper provides the first records of $P$. abruptus and $P$. nicaraguae from South America, as well as the first confirmed data for the genus Palaestes from Peru. Discovery of one of these species was possible thanks to the data collected through the iNaturalist database, which confirms the high value of citizen science in studying biodiversity. Summarising all data mentioned above, we can conclude that the flat bark beetle fauna of South America comprises one subfamily (Platisinae), two genera (Palaestes and Thesaurus) and at least eight species (Table 1, Fig. 5). Three species are recorded from Ecuador and Peru and one species each from Brazil and Venezuela. Surprisingly, no species have been recorded from the remaining South American countries, despite apparently suitable environments being present in Venezuela, Colombia and Bolivia, at least. Two South American species: P. nigriceps Waterhouse, 1880 and $P$. tenuicornis Waterhouse, 1880 from Ecuador have not been recorded from this area since the $19^{\text {th }}$ century, while $P$. freyreissi (von Heyden, [1827]) has not been recorded from Brazil for almost one hundred years. 
Table 1.

Checklist of Cucujidae known from individual countries of South America (countries with no species recorded were not included).

\begin{tabular}{|c|c|c|c|c|c|}
\hline \multicolumn{2}{|c|}{ Species } & \multicolumn{4}{|c|}{ Country } \\
\hline 1. & Palaestes abruptus Sharp, 1899 & Brazil & Ecuador & $\begin{array}{l}\text { Peru } \\
+ \\
\end{array}$ & Venezuela \\
\hline 2. & Palaestes nicaraguae Sharp, 1899 & & & + & \\
\hline 3. & Palaestes freyreissi (von Heyden, [1827]) & + & & & \\
\hline 4. & Palaestes nigriceps Waterhouse, 1880 & & + & & \\
\hline 5. & Palaestes tenuicornis Waterhouse, 1880 & & + & & \\
\hline 6. & Thesaurus albertalleni Jin, Zwick, Ślipiński, Marris, Thomas \& Pang, 2020 & & & & + \\
\hline 7. & Thesaurus macclarini Jin, Zwick, Ślipiński, Marris, Thomas \& Pang, 2020 & & + & & \\
\hline 8. & Thesaurus zaitsevi Jin, Zwick, Ślipiński, Marris, Thomas \& Pang, 2020 & & & + & \\
\hline \multicolumn{2}{|c|}{ Total } & 1 & 3 & 3 & 1 \\
\hline
\end{tabular}

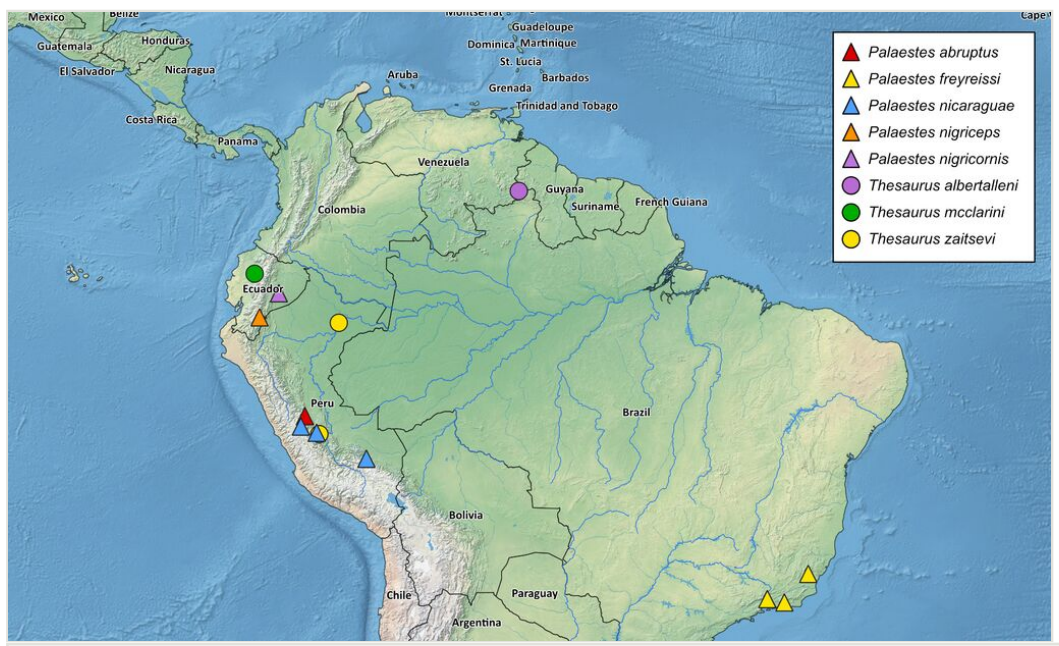

Figure 5. doi

Distribution of Cucujidae in South America.

The two new species records, reported here, highlight the poor state of knowledge of Cucujidae in South America and for the genus Palaestes over its wider distributional range (which includes Central America). Most of the published distribution information for Palaestes is from the original species descriptions, the most recent of which dates back to 1899. Since that time, the only publications discussing Palaestes were reliant on the same locality data as given in the descriptions (viz. Hetschko 1930, Blackwelder 1945). Various entomology collections contain examples of Palaestes, which are known to extend the range of distribution records, but these have yet to make it into the scientific literature 
(Marris, Jaskuła, unpublished data). It is highly likely that further, targeted collecting in appropriate habitats will yield new taxa. This likelihood is emphasised by the recent discovery (the first specimen was collected in 1997) and description of the new genus, Thesaurus, with three new species from South America. It is remarkable that, despite more than 220 years of collecting on the continent, these relatively large and distinctive beetles had evaded discovery. Similarly, the state of taxonomy of Palaestes species is overdue for revision and there are no keys or modern identification aids available for the genus. The identifications of the two species recorded here are based solely on the original descriptions and photographs of the type material. Examination of existing collection material and detailed, critical analysis of the genus will likely show that new species are present. Both species, recorded here, have been identified as species otherwise known only from localities in Central America, separated by more than $2000 \mathrm{~km}$ in a straight line and crossing major geographical barriers. Hopefully, with more emphasis given to surveying for these beetles across Central and South America, more will be revealed about the ecology and biology of both the larvae and adults, as well as providing more information on the range of these distinctive and remarkable beetles.

\section{Acknowledgements}

We would like to thank to Andrey Azarov (Moscow, Russia) and Pavel Udovichenko (Moscow, Russia) for sending Palaestes beetles used in this study, as well as to Alexander Petrov (Institute of Forest Science Russian Academy of Science, Uspenskoe, Russia) and Alexander Sokolov (Moscow, Russia) for sending pictures of the habitat of $P$. nicaraguae and $P$. abruptus, respectively.

\section{Author contributions}

Radomir Jaskuła - research conceptualisation, investigation and data collection, data analysis and interpretation, writing - original draft, review \& editing; Marek Michalski writing - original draft, review \& editing; John W. M. Marris - investigation and data collection, writing - original draft, review \& editing

\section{References}

- $\quad$ Beck HE, Zimmermann NE, McVicar TR, Vergopolan N, Berg A, Wood EF (2018) Present and future Koppen-Geiger climate classification maps at 1-km resolution. Scientific Data 5: 180214.

- Blackwelder RE (1945) Checklist of the coleopterous insects of Mexico, Central America, The West Indies, and South America. Part 3. U.S. National Museum, Smithsonian Institution, Washington, $207 \mathrm{pp}$.

- Bonacci T, Mazzei A, Horák J, Brandmayr P (2012) Cucujus tulliae sp. n. - an endemic Mediterranean saproxylic beetle from genus Cucujus Fabricius, 1775 (Coleoptera, 
Cucujidae), and keys for identification of adults and larvae native to Europe.

ZooKeys 212: 63-79.

- Bonacci T, Rovito M, Horák J, Brandmayr P (2020) Artificial reeding and laboratory rearing of endangered saproxylic beetles as a yool for insect conservation. Journal of Insect Science 20 (5): 1-7.

- Bussler H (2017) Cucujus muelleri sp. n. aus den kaspischen Gebirgswaldern des Iran (Coleoptera: Cucujidae). Nachrichtenblatt der Bayerischen

Entomologen 66 (3-4): 54-58.

- Gray GR (1832) Notices of new genera and species. In: Griffith E, Pidgeon E (Eds) The animal kingdom arranged in conformity with its organization by the Baron Cuvier. Vol.

14 (Insecta, vol. 1). London, 570 pp.

- Guérin-Méneville FE (1844) Iconographie du règne animal de G. Cuvier. Vol. 7, Insectes, 1829-1838 (1844). J. B. Baillière, Paris-London, 576 pp.

- Háva J, Zahradník P, Růžička T (2019) A new species of genus Cucujus Fabricius, 1775 (Coleoptera: Cucujidae) from China. Natura Somogyiensis 33: 129-134.

- Hetschko A (1930) Cucujidae, Thorictidae (Suppl.), Cossyphodidae (Suppl.). Pars 109. In: Junk W, Schenkling S (Eds) Coleopterorum catalogus. W. Junk, Berlin, 122 pp.

- Horák J, Chobot K (2009) Worldwide distribution of saproxylic beetles of the genus Cucujus Fabricius, 1775 (Coleoptera: Cucujidae). In: Buse J, Alexander KNA, Ranius T, Assmann T (Eds) Saproxylic Beetles: Their Role and Diversity in European Woodland and Tree Habitats: Proceedings of the 5th Symposium and Workshop on the Conservation of Saproxylic Beetles. Pensoft Publishers, Sofia-Moscow, 235 pp.

- Horák J, Nakládal O (2009) Beetles associated with trees and predation between them: Part III. Annotated checklist of beetles with predation potential. Lesnícky Časopis Forestry Journal 55: 181-193.

- Horák J (2011) Contribution to knowledge of diet preferences of the endangered saproxylic beetle Cucujus cinnaberinus (Coleoptera: Cucujidae) from East Bohemia. Acta Musei Reginaehradecensis S. A. 33: 127-130.

- Hsiao Y (2020) A taxonomic study of Cucujus Fabricius, 1775 from Asia (Coleoptera: Cucujidae), with descriptions of new species and notes on morphological classification. Insect Systematics and Evolution1-51. https://doi.org/10.1163/1876312X-bja10012

- Jaskuła R, Michalski M, Acal DA (2020) First record of the family Cucujidae (Insecta: Coleoptera) from Vietnam with a checklist and a key to species currently known from Indochinese Peninsula. Oriental Insects https://doi.org/10.1080/00305316.2020. 1839589

- Jin M, Zwick A, Ślipiński A, Marris JW, Thomas MC, Pang H (2020) A comprehensive phylogeny of flat bark beetles (Coleoptera: Cucujidae) with a revised classification and a new South American genus. Systematic Entomology 45: 248-268.

- Lee CF, Satô M (2007) A review of the genus Cucujus Fabricius (Insecta: Cucujoidea: Cucujidae) from Taiwan, Japan, and China, with descriptions of two new species and the larvae of Cucujus mniszechi Grouvelle. Zoological Studies 46 (3): 311-321.

- Lee CF, Pütz A (2008) A new species of Cucujus Fabricius, 1775 from China and key to the east-Palaearctic species of the genus (Coleoptera: Cucujidae). Entomologische Zeitschrift 118 (5): 211-213.

- Lee J, Thomas MC (2011) Clarification of the taxonomic status of Cucujus clavipes with descriptions of the larvae of C. c. clavipes and C. c. puniceus (Coleoptera: Cucujidae). Florida Entomologist 94: 145-150. 
- $\quad$ Mamaev BM, Krivosheina NP, Pototskaya VA (1977) Opredelitel' lichinok khishchnykh nasekomykh-entomofagov stvolovykh vrediteley. [Key to larvae of insects-predators of tree trunks pests]. Izdatelstvo Nauka, Moscow, 39 pp. [In Russian].

- Marris JW, Ślipiński A (2014) A revision of the Pediacus Shuckard 1839 (Coleoptera: Cucujidae) of Asia and Australasia. Zootaxa 3754: 32-58.

- Marris JW (2017) A revision of the flat bark beetle genus Platisus Erichson, 1842 (Coleoptera: Cucujidae). Austral Entomology 56: 277-295.

- $\quad$ Mazzei A, Bonacci T, Contarini E, Zetto T, Brandmayr P (2011) Rediscovering the umbrella species candidate Cucujus cinnaberinus (Scopoli, 1763) in Southern Italy (Coleoptera Cucujidae), and notes on bionomy. Italian Journal of Zoology 78: 264-270.

- Myers N, Mittermeier RA, Mittermeier CG, Da Fonseca GA, Kent J (2000) Biodiversity hotspots for conservation priorities. Nature 403: 853-858.

- Nikitskiy NB, Bibin AR, Dolgin BB (2000) Ksilofilniye zhestkokryliye (Coleoptera) Kavkazskogo Gosudarstvennogo Prirodnogo Biosfernogo Zapovednika i sopredelnykh territorii. Syktyvkar, Moscow, 452 pp. [In Russian].

- $\quad$ Palm T (1941) Über die Entwicklung und Lebensweise einiger wenig bekannten KäferArten im Urwaldgebiet am Fluss Dalälven (Schweden) II und III. Opuscula Entomologica 6: 17-26.

- Perty M (1830) Delectus animalium articulatorum, quae in itinere per Brasiliam annis MDCCCXVII - MDCCCXX jussu et auspiciis Maximiliani Josephi I. Bavariae Regis Augustissimi peracto. Collegerunt Dr. J.B. de Spix, et C.F.Ph. de Martius. Digessit, descripsit, pingenda curavit Maximilianus Perty, Praefatus est et edidit C.F.Ph. de Martius. Monachii, impensis Editoris, Munich-Leipzig, 224 pp.

- Sharp D (1899) Cucujidae. In: Godman FD, Salvin O (Eds) Biologia Centrali-Americana, Insecta. Coleoptera Vol. II. Part 1. Taylor and Francis, London, 696 pp.

- $\quad$ Smith DB, Sears MK (1982) Mandibular structure and feeding habits of three morphologically similar coleopterous larvae: Cucujus clavipes (Cucujidae), Dendroides canadensis (Pyrochroidae), and Pytho depressus (Salpingidae). The Canadian Entomologist 114: 173-175.

- Thomas MC (2003) A revision of Pediacus Shuckard (Coleoptera: Cucujidae) for America north of Mexico, with notes on other species. Insecta Mundi 17 (3-4): 157-177.

- Thomas MC, Leschen RA (2010) 10.15. Cucujidae Latreille, 1802. In: Leschen RA, Beutel RG, Lawrence JF (Eds) Handbook of Zoology, Arthropoda: Insecta, Coleoptera, Beetles. Vol. 2: Morphology and Systematics (Elateroidea, Bostrichiformia, Cucujiformia partim). Walter de Gruyter, Berlin, $786 \mathrm{pp}$.

- Thomas MC, Chaboo CS (2015) Beetles (Coleoptera) of Peru: a survey of the families. Cucujidae, Laemophloeidae, Silvanidae, Passandridae (Cucujoidea). Journal of the Kansas Entomological Society 88 (2): 25.

- $\quad$ von Heyden CH (1827) [description of:] Cucujus freyreisii sp. n. In: Mappes JM (Ed.) Zum Andenken an Georg Wilhelm Freyreiß; zugleich Bericht über den innern Zustand der Gesellschaft seit dem 1. Mai 1825. Rede, vorgetragen in der öffentlichen Sitzung zur Jahresfeier am 1. Mai 1826, von den Secretair der Gesellschaft, Hrn. Dr. Mappes. Iris: Unterhaltungsblatt für Freunde des Schönen u. Nützlichen.

- Waterhouse CO (1880) New South-American Coleoptera, chiefly from Ecuador. The Annals and Magazine of Natural History 15 (28): 285-302. 
- Watt JC, Marris JW, Klimaszewski J (2001) A new species of Platisus (Coleoptera: Cucujidae) from New Zealand, described from the adult and larva. Journal of the Royal Society of New Zealand 31: 327-339.

- Zdeněk B, Turcani M, Horak J (2012) Sharing the same space: Foraging behaviour of saproxylic beetles in relation to dietary components of morphologically similar larvae. Ecological Entomology 37: 117-123.

- Zhao MZ, Zhang JK (2019) Contribution to the knowledge of the genus Cucujus Fabricius (Coleoptera, Cucujidae) from China. Zootaxa 4544 (1): 144-150. 